Norton, E., Holloway, I., Galvin,K. 2013.

\begin{abstract}
Comfort versus risk: A grounded theory about female adolescent behaviour in the sun
\end{abstract}

\title{
Aims and objectives
}

The aim was to generate a grounded theory about female adolescent behaviour in the sun.

\section{Background}

Nurses have key roles in health promotion and skin cancer prevention. Adolescents' resistance to sun safety messages and their vulnerability to sunburn is of concern internationally. Understanding why young women do as they do in the sun may enhance skin cancer prevention but their behaviour has not been explained before in the UK.

\section{Design}

The study incorporated a qualitative grounded theory design using the approach of Glaser. 


\section{Methods}

Qualitative data were gleaned from group and one-to-one, semi-structured interviews with 20 female participants aged 14 to 17, research memos and literature. Sampling was purposive and theoretical. Data collection, analysis and theory generation occurred concurrently. Data were analysed using the constant comparative method. Data collection ended when a substantive theory had been generated.

\section{Results}

Data analysis revealed five categories of findings: Fitting In, Being Myself, Being Physically Comfortable, Slipping Up and Being Comfortable (the core category). The theory generated around the core explains how young women direct their sun-related activities toward meeting their physical and psychosocial comfort needs.

\section{Conclusions}

A contribution of this research is the grounded theory explaining the behaviour of young women in the sun. Further, the theory challenges assumptions that female adolescents necessarily take risks; it explains their sun-related activities in terms of comfort. The theory extends findings from other researchers' descriptive qualitative studies and also appears to apply to young people in countries other than the UK. 


\section{Relevance to clinical practice}

Understanding the sun-related activity of young women in terms of physical and psychosocial comfort may help nurses to develop new approaches to skin cancer prevention. These could complement existing messages and humanise health promotion. 


\section{What does this paper contribute to the wider global clinical community?}

- It increases understanding of female adolescent sun-related behaviour and offers a theory to explain it. Nurses and others may use the insights gained from this study to develop new approaches to skin cancer prevention and to humanise health promotion.

- Although developed in the UK context, the grounded theory appears to be transferable to young people in countries other than the UK where sun exposure as a risk factor for skin cancer prevention is an issue; there is scope to investigate this through collaborative, international research.

- The paper challenges assumptions that female adolescents necessarily take risks: the grounded theory explains their activities in terms of their comfort.

\section{Keywords}

Adolescent sun-related behaviour; comfort; nursing; primary prevention; skin cancer; public health; grounded theory; qualitative research; health promotion; sun safety 


\section{INTRODUCTION}

Skin cancer poses an international public health problem (Hart \& DeMarco 2008) with significant percentages of newly diagnosed cancers in Australia and the UK being skin cancers: $80 \%$ (Cancer Council Australia 2012) and approximately 25\% (National Cancer Intelligence Network 2010) respectively. An important risk factor in the development of skin cancers is sun exposure (The Royal College of Physicians 2007, Young 2009) and sun exposure in formative years has been linked to the development of skin cancer in later life (Whiteman et al. 2001, World Health Organisation 2007). It has been recognised that skin cancer prevention should begin in childhood (Hoang \& Eichenfield 2000, Filiz et al. 2006). However sunlight has a role in Vitamin D synthesis and so sun protection and exposure should be balanced (Panou et al. 2012). Current advice is to engage in sun exposure without burning (Cancer Research UK (CRUK) 2012) however sunburn is prevalent in adolescents (Alberg et al. 2002, Davis et al. 2002, El Sayed et al. 2006).

National and international skin cancer prevention strategies have incorporated sun awareness campaigns (CRUK 2009, Paul et al. 2008) but evidence indicates that increased knowledge does not always translate into sun-related behaviour change (Calder \& Aitken 2008, Hart \& DeMarco 2008, Paul et al. 2008). Young people's behaviour in particular has been identified as resistant to health education (Melia et al. 2000, Hart \& DeMarco 2008). They are unlikely to protect themselves in the sun (Geller et al. 2005, Livingston et al. 2007) and are difficult to 'reach' (Marks 1999, Montague et al. 2001, Potente et al. 2011). Nurses have a significant role in promoting the health of young people (Curtis \& Pollock 2009) and preventing skin 
cancer (Boe \& Tillotson 2006) but more in-depth research is needed (Paul et al. 2008) to investigate factors that promote and impede adolescents' sun protection (Dobbinson et al. 2008). Further, UK-based studies are required (Curtis \& Pollock 2009) because climate influences sun-related perceptions and behaviours (Howard 1997) and research findings from other countries might not transfer.

\section{BACKGROUND}

Understanding why people do what they do can inform health interventions (Leary et al. 1994). Although qualitative studies facilitate understanding of others' behaviours and perceptions (Holloway 2005) there has been little qualitative research exploring adolescents' behaviours in the sun particularly in the UK (Curtis \& Pollock 2009). At the beginning of the study (undertaken between 2002-08) one peer-reviewed qualitative study about adolescents and their sun-related behaviour existed, and this was Australian. The descriptive study by Lupton \& Gaffney (1996) involved 50 girls and 48 boys aged 11-16. It explored perceptions about sun tanning and sun protection. The researchers found that influences on sun tanning and sun protection included the attractiveness and implications of a suntan, the role of a tan in being accepted, appearance issues, parents, fashion issues and negative perceptions of sun protection.

Although there has been subsequent grounded theory research involving adolescents of both genders in Canada (Shoveller et al. 2003) descriptive qualitative investigations into sun protection with both genders in Australia (Paul et al. 2008, Potente et al. 2011) and descriptive qualitative research into sun exposure with 
females in the UK (Curtis \& Pollock 2009) it appears that no qualitative study has explored the experiences of UK female adolescents specifically with the intention of producing a theory to explain their behaviour. It was anticipated at the beginning of this study that such exploration and explanation could inform skin cancer prevention work of nurses and others involved with teenagers' health. Hence the aim of this research was to explore UK young women's sun-related experiences and to generate a grounded theory to explain their behaviours in the sun. To facilitate in-depth exploration the study only included females. Compared to male adolescents, females have more positive attitudes to sun tans (Wichstrøm 1994) a predilection to sunbathe (McGee \& Williams 1992, Wichstrøm 1994) and a tendency to experience their most serious sunburns through sunbathing (Davis et al. 2002).

\section{METHODS}

A qualitative research design incorporated grounded theory method because this seeks to discover why people do as they do (Glaser 1998) and results in explanatory theory. In this study the version of grounded theory developed by Glaser was used because it facilitates exploration of participants' issues and emphasises their perspectives (Glaser 1992).

Young women were the main source of the data, which was gained through semistructured interviews. Sampling was purposive and theoretical, beginning with a purposive sample of girls aged 14-15 years old. Girls of this age were likely to have had experience of independence from adults; it is then that their sun protection attitudes and behaviours are believed to decline (Dixon et al. 1999, Roberts \& Black 
2009). Developmental issues may also influence sun-related behaviours for example when appearance becomes an issue (Jones et al. 2000, Marcoux 2000). Other than age, there were no inclusion criteria based on the assumption that all teenaged girls would have had experience of being in the sun. No exclusion criteria were applied in order to be inclusive (a condition of ethical approval).

Theoretical sampling was necessary to develop theory that emerged during data analysis (Glaser \& Strauss 1967). Based on emerging issues there was a need to access new participants with insight, discuss issues further with past participants, revisit existing data and seek relevant literature (Wuest 2012). The final sample comprised 20 female participants aged $14-17$ years. The 20 participants formed six interview groups, each comprising three to five members.

Volunteers were recruited from two school and two youth work settings in a southern coastal region of the UK. Access to potential participants was negotiated with head teachers and youth workers. Where possible, before inviting potential participants to become involved the principal researcher (E.N.) visited them and introduced herself. Those wishing to volunteer informed their teacher or youth worker to prevent them feeling under pressure to contribute. They knew that the study was to investigate how teenagers behave in the sun, aimed to improve the way adults work with young people and that it would involve small group discussion and one-to-one interviews if they were willing.

The study was approved by the relevant UK, National Health Service Ethics Committee. Consent to participate in the study had legal and ethical bases; written 
consent was gained from the volunteers as well as from those with parental responsibility as advised by Allmark, (2002) and the Market Research Society (2012). Organisations' policies and procedures for safeguarding children were followed. Study information given to volunteers was specifically tailored in terms of style and language. The participants' confidentiality was protected by anonymising data and by ascribing pseudonyms. The main researcher transcribed the taped interview data. Details of participants and their identities were stored securely and all data kept according to data protection legislation and university protocols.

Interviews took place in participants' school and youth club settings. Developing rapport with participants was important as suggested by (Charmaz 2006) and group interviews were used to balance the power relations between the participants and the main researcher (as advocated by Kitzinger \& Barbour (1999)). Focus group interview technique was used to explore, listen to and learn from the volunteers (Holloway \& Wheeler 2010). The interview guide was open so that participants' issues would emerge. Open questions initiated conversations and Cancer Research UK advice cards about sun safety provided triggers for exploring what the young women did or did not do in the sun and why. Discussions lasted 20 minutes to an hour and participants' verbal accounts comprised the data. When volunteers had consented to be tape-recorded, tapes were transcribed verbatim (no outsider was involved in the transcription). Volunteers who had not consented to taped discussions agreed to notes being taken by the interviewer $(\mathrm{EN})$. Notes were extended immediately after interviews to capture maximum detail. 
In total 13 group interviews were carried out, and five of the six groups met on at least two occasions. This enabled a member check with participants. After the group meetings six individuals were interviewed on their own. This gave the opportunity to follow up the understanding of issues that had been emerging in the data analysis and a chance for individuals to add their perspectives away from peers. Data sources other than interviews included memos (notes made about interviewing and analytic processes, experiences, environmental observations and influences) and literature related to issues that had emerged from participants' perspectives during data analysis.

During the study, data collection, analysis and theory generation occurred simultaneously. Data analysis was carried out manually, utilised the constant comparative method and involved open and theoretical coding processes. Five main categories were derived from the data (Figure one): Fitting In, Being Myself, Being Physically Comfortable, Slipping Up and Being Comfortable. Being Comfortable emerged as the core category or main issue for participants during a group discussion. This established that sun safety was not a natural part of their agenda, comfort was. Review of data from previous interviews revealed that needing to be comfortable had been a main theme from the beginning of the study. Ruth for example had said that she would not be comfortable if she thought she looked 'stupid' because of her appearance.

Following identification of the core category theoretical coding was used to develop the theory. Theoretical coding proposes relationships between categories based on 'coding families' (Glaser 1978). Relative to the core, the categories Fitting In, Being 
Myself, Being Physically Comfortable, and Slipping Up indicated conditions and strategies for being comfortable, consequences of being comfortable and contextual issues. A grounded theory based on these elements was written conceptually as advised by (Wuest 2012).

Data collection and analysis ceased when extra data did not reveal new issues and the research aim for a substantive, explanatory theory had been achieved. Although the categories had reached 'saturation' the opportunity to develop the grounded theory remains (Glaser \& Strauss 1967).

The research process was evaluated in an on-going reflexive way to ensure rigour as advocated by Morse (et al. 2002). The criteria of fit, relevance, modifiability and work were used to assess research trustworthiness during the study as suggested by Glaser (1978). For example, 'fit' refers to the data naturally relating to the theory rather than being forced to correspond (Glaser 1978). During data analysis new data was not forced to fit existing categories rather categories were reviewed and developed to accommodate it.

\section{RESULTS}

The four categories Fitting In, Being Myself, Being Physically Comfortable, Slipping $U p$ are presented below followed by the grounded theory constructed around the core, Being Comfortable. 


\section{Fitting in}

Participants needed to be socially acceptable in a context where appearance mattered. They needed to meet the expectations of their peers and their wider social context and they adopted behaviours and 'looks', expected of them by peers; 'fitting in' depended on conforming to an agenda that included having to look good and to have a suntan in the summer. The importance of physical appearance was relayed indirectly via the media and celebrities. As Molly had commented: 'You don't see Victoria Beckham all pale blotchy and in trackie bottoms!' .

There were leaders within peer groups referred to as 'The Barbies' or 'The Plastics'. 'The Plastics' copied celebrities, they were fashionable and popular, they 'thought they were pop stars' and they set the trends for others by wearing 'the latest, latest fashion'. 'Plastics and Barbies' were followed by peers referred to as 'The Sheep' (the participants' words) so called because 'they just tag along', 'they want to be the leaders' and they are '“yes' people'.

Because a person's appearance drew peer attention it was desirable for individuals to stand out because they looked good. It was undesirable to stand out as a consequence of 'looking bad' or 'stupid' hence strategies to increase the likelihood of being accepted led the young women to improve their appearance and avoid negative attention derived from 'looking bad'. Sun-related appearance was subsumed within the appearance agenda and it influenced an individual's propensity to stand out positively or negatively; a suntan could enhance appearance but being sun burned meant that an individual stood out for the wrong reasons. 
The need to conform and fit into the appearances agenda was driven by concern or 'worry' about what might happen if participants did not comply. Potential consequences included feeling hurt, being mocked, feeling embarrassed and feeling insecure. Fears were based on experience; for example Emily described how she had felt hurt when friends had teased her about an item of clothing she had been wearing. Worry also derived from anticipation of what others might be thinking.

Ruth: ... Even if you're not (the laughing stock of the whole camp), you think you are, which is probably, sort of quite a big part of it ...

There were limits to fitting in to the appearances agenda, and concern about what others thought of one's appearance varied. The ability to be different derived from having been accepted by others as Helen described:

... you don't really care about not fittin' in because you know that you've got your mates now and you know that they're gonna stick around for you.

Self-confidence and learning from experience were also implicated and these attributes may have developed with age. Older participants (aged 16-17 years) had learned the necessity for sun protection through negative experiences. There were accounts of being badly sunburned as a result of being more concerned about what others thought or by forgetting to protect in the sun. Queenie told of how 'you find out in the end' by testing things out and learning from mistakes. 


\section{Being myself}

The young women needed to follow their own personal agendas, for example being in the sun was part of who Ann was:

Ann: ... I've always been in the sun right, ever since I was little though.

Interviewer: (clarifying) So you just see it as a natural thing to do. Ann: Yeah, like every summer ever since I was little, going down the beach every year.

There were consequences of the participants' agendas for sun safety as the sun safety code was perceived as 'asking too much', punitive and 'extreme'. Advice to stay in the shade between 11 in the morning and three in the afternoon clashed with the girls' desires to make the most of sunny days with friends.

Overall it emerged that participants were individuals with diverse agendas, behaviours and preferences in the sun indicating that they did not comprise a homogeneous group. Perceptions of the relevance of sun safety varied and when the risk of skin cancer was perceived to be 'real' or there could be physical discomfort or harm from sun exposure, the sun safety code emerged as more appropriate. However the issues were complex since individuals did not behave in one consistent, 'adolescent' way; they 'acted the part' assuming the role of child, adolescent or adult according to whose company they were in; and this influenced their sun-protection behaviours. For example with adults, they assumed the role of dependent child and responded to 
adults' requirements to protect from the sun's rays. As Queenie explained (referring to sun cream and jokingly sounding frustrated):

You have to do everything to the maximum, everything to the extreme, put on twenny times what normally you'd put on.

Although participants did not always apply sun safety advice to themselves, they took more adult, protective roles when they were with younger children. They perceived that they needed sun safety knowledge for these occasions.

In the company of their peers participants took more responsibility for themselves, adopting 'adolescent' roles. This influenced their sun protection given the lack of adults' reminders and sun-protection equipment. Despite good intentions sun protection could be forgotten when individuals became engrossed in outside activities and it could also be influenced by peers.

\section{Being physically comfortable}

It was important for participants to feel physically comfortable when they were in the sun; they liked to feel pleasantly warm but not too hot. The young women used two main strategies to maintain their physical comfort and one involved planning to prevent the adverse physical effects of sun exposure. Wearing hats and sun cream emerged as main methods of planned protection although the sun creams applied generally afforded sun protection lower than the recommended minimum of SPF 15. 
This was because sun protection factor SPF 15+ was viewed as excessive. The second more spontaneous and more common approach to maintaining physical comfort relied upon participants reacting to feelings of physical discomfort. For example Ruth and Queenie explained their reasons for seeking shade:

Ruth: ... it's so hot that you want to go in, so, it's not necessarily because it's lunchtime.

Queenie: Yeah, it's just because you feel uncomfortable. You started gettin' uncomfortable.

Both planning and avoidance tactics could be limited by the social acceptability of comfort solutions. For example, sunglasses were avoided because of the unattractive marks they could leave behind and hats were advocated for those they suited.

\section{Slipping up}

Sunburn led to experiences of psychosocial and/or physical discomfort in the form of derision by peers, embarrassment and the physical pain of sunburn.

Queenie: You always know that people will laugh at you if you're red so you don't wanna do it. You know you laugh at other people so ...

Ruth : Yeah, I s'pose it's kind of this image conscious of being burnt I s'pose, Queenie: Yeah. 
Ruth: So I don’t wanna look red, so ..

Interviewer: I was gonna say, what's the big thing about being

burnt? but you think it might be an image thing (clarifying).

Queenie: Yeah.

Ruth: Yeah, but also it's really painful.

Although participants believed that sunburn should be avoided and they protected themselves to this end, they could be caught out. They 'slipped up' for two reasons; they could misjudge their environmental conditions and they could forget to protect themselves from ultraviolet radiation (UVR). Misjudgement stemmed from lack of knowledge about the nature of UVR and the conditions leading to exposure. On cloudy or windy days for example, the young women did not perceive a need to protect themselves from UVR because they could not feel the sun's heat. This comment from Carly illustrates:

... I was just walkin' in the streets and it was so cloudy, and it was like near to rain ... I didn't feel the sun on me, but then like the next day, all of my knees (giggles) and my shins were really sore.

Being in the sea or swimming pools posed similar conditions and participants had burned because they had been unaware that ultraviolet radiation could penetrate water.

The experience of sunburn did not lead to prevention because participants simply forgot when out, busy with peers, absorbed in their own agendas. 
Isabel: When you're out there 'nd you're having a good time, things slip your mind.

Linda: You just don't remember.

\section{The theory of female adolescents' behaviours in the sun}

Needing to be comfortable influences the perceptions and behaviours of young women when they are both in and out of the sunshine. The need for comfort can be conscious and/or subconscious and can have physical and/or psychosocial components. Whilst physical comfort in the sun depends upon the absence of unpleasant sensations such as feeling sun burnt or uncomfortably hot, Being Comfortable from a psychosocial perspective reflects feelings of psychological and social ease. For some young women, psychosocial ease depends upon the belief that their appearance is acceptable to others. They think that an appropriate appearance is necessary for them to be accepted by peers and the wider social community. For these individuals, Being Comfortable (generally, as well as in the sun) requires them to fit in and conform to the social agenda whereby appearances matter. In order to be comfortable, they need to look good and be fashionable and this means enhancing their appearance by gaining a tan in the summer.

If they do not conform to the appearances agenda some individuals worry about what others might think of them and this compromises their psychosocial comfort. Rather than risk negative evaluation, they conform to the appearances agenda because of the perceived consequences. Although a young woman may intend to protect herself from the sun's rays, her intention may falter if she risks social exclusion by doing so. 
Sunburn is avoided because a sunburned appearance leads to negative evaluation by peers and because it can also affect physical comfort by inflicting pain.

Not all young women are influenced by the appearances agenda and some individuals do not feel compelled to look good and have a suntan. They do not want to conform to the appearance agenda and they are not driven by concerns about exclusion. Indeed, being psychosocially comfortable in the first place makes it possible for them to be different; perhaps because they have already been accepted by others, because they have self-confidence or they have learned from experience about the benefits of behaving independently. Being Comfortable depends upon young women being themselves and following their own agendas. Because of this, the issues involved in Being Comfortable in the sun and more generally, differ amongst individuals and may vary according to the company young women find themselves in.

Given that young women need to be comfortable, they behave according to this end. Some of their activities serve to make them feel more comfortable and others prevent experiences of discomfort. Sun protection may be avoided if it is likely to compromise the individual's comfort, for example covering up with clothing to avoid the sun's rays is likely to make the individual feel hotter instead of more comfortable. Further, covering up with an unfashionable garment potentially brings the disadvantages of compromised appearance and psychosocial discomfort. 


\section{DISCUSSION}

The aim of this study was to explore UK female adolescents' sun-related experiences and to generate a grounded theory to explain their behaviours. It appears that no other studies have produced a theory about adolescent behaviours in the sun based on comfort however comfort issues have been cited as influential in some research irrespective of methodology. This may be seen as a source of data to compare with the theory that has emerged. In a quantitative study Brandberg et al. (1998) noted that their Swedish, adolescent participants most frequently gave feeling warm and comfortable as a reason to sunbathe, and in an Australian study Paul et al. (2008) categorised reasons for using sun protection (avoiding heat, the pain of sunburn and avoiding glare) as personal comfort issues. Potente et al. (2011) too found their participants used shade to avoid the heat of the sun and sunglasses to protect themselves from its glare. They also identified comfort as a theme in their findings. However it is not clear in the studies if the terminology of comfort derived from participants' accounts directly as it did in this research.

Internationally, research investigating adolescent sun-related behaviours has tended to view young people as risk takers (de Vries et al. 2005, Lupton \& Gaffney 1996, Wichstrøm 1994) based on adults' definitions of health (MacKinnon 2007). This study offers a different standpoint derived from the perspectives of young women themselves, explaining their activities in terms of physical and psychosocial comfort. Factors influencing their sun-related behaviours are complex and diverse, and although this has been noted before (Andreeva et al. 2008, Potente et al. 2011) the 
grounded theory explains their intricacy. Individuals' behaviours were contextual and could alter in an instant depending on their comfort in different social scenarios.

Research findings which concur with those in this study include a propensity for young people to avoid feeling hot (Paul et al. 2008, Potente et al. 2011) and being reluctant to use clothing as sun protection (Dobbinson et al. 2008) particularly if the clothing is perceived to be unfashionable (Curtis \& Pollock 2009). The theory about Being Comfortable presented above may offer the answer to a question posed in an Australian survey by Dobbinson et al. (2008). The researchers investigated the sunrelated attitudes, sunburn and behaviours of 699 male and female adolescents aged 12-17 at summer weekends. They found that participants did not readily cover up or wear hats to protect in the sun and they queried whether discomfort, peer pressure and social influences such as fashion and youth culture could account for this. Based on the theory developed in this study, not readily covering up or wearing hats could be attributed to all of these factors as they each have the potential to impinge on a young person's physical and/or psychosocial comfort. For example covering up with clothing to avoid the sun's rays is likely to affect physical comfort by making the individual feel hotter instead of more comfortable and covering up with an unfashionable garment potentially brings the disadvantage of compromised appearance and concomitant psychosocial discomfort.

An unexpected outcome of the research has been that the descriptive findings concur with those from Australian and Canadian studies. For example the avoidance of sunburn, the influence of role models and the media on appearance (Shoveller et al. 2003), the significance of fitting in to the social environment (Paul et al 2008, 
Shoveller et al. 2003), forgetting to use sun protection when socialising, the influence of peers and fashion, the desire for suntans and concern about being ridiculed (Paul et al. 2008). This suggests that the theory may be transferable. The grounded theory may also explain the behaviours of people in other age groups in the UK, given comparative findings with the work of Curtis \& Pollock (2009) who found that influences on 12-15 year old girls' sun exposure behaviours included fashion, peers, parents, celebrities, dislike and inappropriate use of sunscreen (Curtis \& Pollock 2009). It may also apply to those older than those aged 14-17 years since findings compare with those of a qualitative study with young adults in New Zealand aged 1822 (Calder \& Aitken 2008). Calder \& Aitken (2008) found that influences on the sun protection of participants included appearance issues, media and celebrity impact, peers, issues of belonging and the negative impact of sunburn. Given these and the similarities above, there is scope to explore the transferability of the theory proposed, with people from older and younger age groups and through collaborative international research.

Although a strength of the research was its inductive nature there were study limitations. For example the semi-structured interviews relied on self-report by the participants and the young women were aware of the nature and purpose of this study from the outset. However Lower et al. (1998) and Dobbinson (2008) have found agreement between self-reports and direct observation and participants' accounts did not reflect that they were being tailored to what the researcher might have wanted to hear. 


\section{CONCLUSIONS}

This in-depth, exploratory research with UK female adolescents provides insight into the factors that influence the sun-related activities of young women and its main contribution is a grounded theory to explain their behaviours. The theory challenges assumptions that female adolescents necessarily take risks; it explains their sunrelated activities in terms of their comfort. This is another contribution of the research in the field. The essence of the theory is that when in the sun, young women direct their activities toward meeting physical and psychosocial comfort needs; they seek comfort through the ways in which they behave. Adolescents have poor sun protection practices and this has attracted international concern. The theory proposed in this study offers an explanation as to why this might be and also appears to apply to countries other than the UK.

The issues that influence young women are complex and primary prevention of skin cancer interventions need to reflect the holistic concept of health to which they apparently subscribe. The grounded theory can inform the health promoting activities of nurses and other healthcare workers. For example by understanding the perspectives of young women and using this understanding when designing skin cancer prevention initiatives, nurses may begin to humanise skin cancer prevention as explained in the next section. 


\section{RELEVANCE TO CLINICAL PRACTICE}

Recently the consideration of comfort in nursing has become consigned to end-of-life care rather than every stage of care (Lin 2010). An implication of this study for practice is that comfort has significance in the context of health promotion and skin cancer prevention. It appears that skin cancer prevention interventions for young women need to account for their physical and psychosocial comfort needs including their need to belong. Whilst existing sun safety messages have value they have limitations.

Todres et al. (2009) have suggested humanising healthcare by putting people as human beings at its centre. They advocate the use of qualitative evidence in this process. Whilst epidemiological evidence determines sun exposure as a danger and underpins primary skin cancer prevention interventions, the evidence from the young women in this study indicated other concerns and a more holistic conception of health including psychosocial aspects.

School nurses need to be creative in their attempts to influence sun protection (Curtis \& Pollock 2009) and the implications of this study are that they (and other professionals) could specifically explore how psychosocial and physical comfort needs impact on individuals' sun-related behaviours. They could work together with young women to establish individualised, realistic sun safety options being cognisant of the influences upon them. Further, given that young people are not necessarily aware of the influences upon them (Crossley 2001) nurses in school could help young women to develop such insight as they have the opportunity to talk to young people 
on their own terms (Wainwright et al. 2000). Education to facilitate self-confidence and self-esteem is implicated in issues related to body image (All Party Parliamentary Group (APPG) on Body Image 2012) and may contribute to young women feeling more comfortable with and in themselves. Clearly such education cannot be the sole responsibility of nurses and health professionals. Further, nurses alone cannot address the effects of ideals of body image on health; a strategic approach is needed. In the UK an All Party Parliamentary Group on Body Image has recently instigated debate and action around appearance ideals in partnership with others (APPG on Body Image 2012) so this could be movement in the right direction.

\section{REFERENCES}

Alberg AJ, Herbst RM, Genkinger MHS \& Duszynski BA (2002) Knowledge attitudes, and behaviours toward skin cancer in Maryland youths. Journal of Adolescent Health 31, 372-377.

All Party Parliamentary Group on Body Image (2012) Welcome to the APPG on body image. All Party Parliamentary Group on Body Image. Available at: http://ymca.co.uk/bodyimage (accessed 29 April 2013).

Allmark P (2002) The ethics of research with children. Nurse Researcher 10, 7-19.

Andreeva VA, Reynolds KD, Buller DB, Chou C \& Yaroch AL (2008)

Concurrent psychosocial predictors of sun safety among middle school youth. Journal of School Health 78, 374-381. 
Boe K \& Tillotson EA (2006) Encouraging Sun Safety for Children and Adolescents. The Journal of School Nursing 22, 136-140.

Brandburg Y, Ullen H, Sjöberg L \& Holm LE (1998) Sunbathing and sunbed use related to self-image in a randomized sample of Swedish adolescents. European Journal of Cancer Prevention 7, 321-329.

Calder N \& Aitken R (2008) An exploratory study of the influences that compromise the sun protection of young adults. International Journal of Consumer Studies 32, $579-587$.

Cancer Council Australia (2012) Skin cancer facts and figures. Cancer Council Australia, Australia. Available at:

http://www.cancer.org.au/cancersmartlifestyle/SunSmart/Skincancerfactsandfigures.h $\underline{\text { tm }}$ (accessed 8th May 2013).

Cancer Research UK (2009) SunSmart campaign strategy. Cancer Research UK, UK. Available at:

http://www.sunsmart.org.uk/about-sunsmart/campaignstrategy/ (accessed 8 May 2013).

Cancer Research UK (2012) Vitamin D and skin cancer prevention. Cancer Research UK, UK. Available at:

http://sunsmart.org.uk/advice-and-prevention/vitamin-d/ (accessed 8 May 2013). 
Charmaz K (2006) Constructing a Grounded Theory. A Practical Guide Through Qualitative Analysis. SAGE Publications, London.

Crossley ML (2001) Rethinking psychological approaches towards health promotion. Psychology and Health 16, 161-177.

Curtis B \& Pollock K (2009) Understanding sun exposure in adolescent girls in the UK. British Journal of School Nursing 4, 175-180.

Davis K, Cokkinides V, Weinstock M, O’Connell MC \& Wingo PA (2002) Summer sunburn and sun exposure among US youths ages 11-18: national prevalence and associated factors. Pediatrics 110, 27-35.

De Vries H, Mesters I, van't Riet J, Willems K \& Reubsaet A (2006) Motives of Belgian adolescents for using sunscreen: The role of action plans. Cancer Epidemiology, Biomarkers and Prevention 15,1360-1366.

Dixon H, Borland R \& Hill D (1999) Sun protection and sunburn in primary school children: the influence of age, gender and coloring. Preventive Medicine 28, 119 130.

Dobbinson S, Wakefield M, Hill D, Girgis A, Aitken JF, Beckmann K, Reeder AI, Herd N, Fairthorne A \& Bowles KA (2008) Prevalence and determinants of Australian adolescents' and adults' weekend sun protection and sunburn, summer 2003-2004. Journal of the American Academy of Dermatology 59, 602-614. 
El Sayed F, Ammoury A, Nakhle F, Dhaybi R \& Marguery M (2006) Photoprotection in teenagers. Photodermatology, Photoimmunology and Photomedicine 22, 18-21.

Filiz T, Cinar N, Topsever P \& Ucar F (2006) Tanning youth: knowledge, behaviours and attitudes toward sun protection of high school students in Sakarya, Turkey. Journal of Adolescent Health 38, 469-471.

Geller AC, Shamban J, O’Riordan DL, Slygh C, Kinney JP \& Rosenberg S (2005) Raising sun protection and early detection awareness among Florida high schoolers. Pediatric Dermatology 22, 112-118.

Glaser BG (1978) Advances in the Methodology of Grounded Theory. Theoretical Sensitivity. Sociology Press, California Mill Valley.

Glaser BG (1992) Emergence vs Forcing. Basics of Grounded Theory Analysis.

Sociology Press, California Mill Valley.

Glaser BG (1998) Doing Grounded Theory: Issues and Discussions. Sociology Press, California Mill Valley.

Glaser BG \& Strauss AL (1967) The Discovery of Grounded Theory: Strategies for Qualitative Research. Aldine de Gruyter, New York.

Hoang MT \& Eichenfield LF (2000) The rising incidence of melanoma in children and adolescents. Dermatology Nursing 12, 188-9, 192-3. 
Hart KM \& DeMarco RF (2008) Primary prevention of skin cancer in children and adolescents. Journal of Pediatric Oncology Nursing 25, 67-78.

Holloway I (2005). Qualitative Research in Healthcare. Open University Press, Maidenhead.

Holloway I \& Wheeler S (2010) Qualitative Research in Nursing and Healthcare. 3rd edn. Blackwell Science, Oxford.

Howard W (1997) Attitudes to Sunbathing and the Risks of Skin Cancer. Health Education Authority, London.

Jones F, Harris P \& Chrispin C (2000) Catching the sun: an investigation of sun exposure and skin protective behaviour. Psychology, Health and Medicine 5, 131140.

Kitzinger J \& Barbour RS (1999) Introduction: the challenge and promise of focus groups. In: Developing Focus Group Research: Politics, Theory and Practice (Barbour RS \& Kitzinger J eds.), SAGE Publications, London, pp. 1-20.

Leary MR, Tchividjian LR \& Kraxberger BE (1994) Self-presentation can be hazardous to your health: impression management and health risk. Health Psychology 13, $461-470$.

Lin C (2010) Comfort: A value forgotten in nursing. Cancer Nursing 33, 409-410. 
Livingston PM, White V, Hayman J \& Dobbinson S (2007) Australian adolescents' sun protection behavior: who are we kidding? Preventive Medicine 44, 502-512.

Lower T, Girgis A \& Sanson-Fisher R (1998) The prevalence and predictors of solar protection among adolescents. Preventive Medicine 27, 391-399.

Lupton D \& Gaffney D (1996) Discourses and practices related to suntanning and solar protection among young Australians. Health Education Research 11, 147-159.

MacKinnon D (2007) Health promotion and health education. In: Adolescence and Health (Coleman J, Hendry LB \& Kloep M eds.), John Wiley and Sons Ltd., Chichester, pp. 41-60.

Market Research Society (2012) Guidelines for research among children and young people. Market Research Society, UK. Available at:

http://www.mrs.org.uk/standards/guidelines (accessed 8 May 2013).

Marks R (1999) Two decades of the public health approach to skin cancer control in Australia: why, how and where are we now? Australasian Journal of Dermatology 40, 1-5.

Marcoux D (2000) Appearance, cosmetics and body art in adolescence. Dermatology Clinics 18, 667-673. 
McGee R \&Williams S (1992) Adolescence and sun protection. New Zealand Medical Journal 105, 401-403.

Melia J, Pendry L, Eiser JR, Harland C \& Moss S. 2000. Evaluation of primary prevention initiatives for skin cancer: a review from a UK perspective. British Journal of Dermatology 143, 701-708.

Montague M, Borland R \& Sinclair C (2001) Slip! slop! slap! and sunsmart, 1980 2000: skin cancer control and 20 years of population-based campaigning. Health and Education Behavior 28, 290-305.

Morse J. M, Barrett M, Mayan M, Olson, K \& Spiers J (2002) Verification strategies for establishing reliability and validity in qualitative research. International Journal of Qualitative Methods 1, 1-6.

Name removed to anonymise the manuscript (2008) A grounded theory of female adolescent behaviour in the sun: comfort matters. Name removed to anonymise the manuscript University, UK.

National Cancer Intelligence Network (2010) The importance of skin cancer registration. National Cancer Intelligence Network, UK. Available at: http://www.ncin.org.uk/publications/data_briefings/skin_cancer_registration.aspx (accessed 8 May 2013).

Panou N, Georgopoulos S, Panou M, Sergebtanis G, Maropoulos G \& Papalambros E (2012) Sun exposure and vitamin D. Perspectives in Public Health 132, 7. 
Paul C, Tzelepis F, Parfitt N \& Girgis A (2008) How to improve adolescents' sun protection behaviour? Age and gender issues. American Journal of Health Behavior 32, 387-398.

Potente S, Coppa K, Williams A \& Engels R (2011) Legally brown: using ethnographic methods to understand sun protection attitudes and behaviours among young Australians I didn’t mean to get burnt-it just happened! Health Education Research 26, 39-52.

Roberts DC \& Black D (2009) Comparison of interventions to reduce sun exposure. Behavioral Medicine 35, 67-76.

Shoveller JA, Lovato CY, Young RA \& Moffat B (2003) Exploring the development of sun-tanning behaviour: a grounded theory study of adolescents' decision-making experiences with becoming a sun tanner. International Journal of Behavioral Medicine 10, 299-314.

The Royal College of Physicians (2007) Concise Guidance to Good Practice. Number Seven. The Prevention, Diagnosis, Referral and Management of Melanoma of the Skin. Royal College of Physicians, London.

Todres L, Galvin K \& Holloway I (2009) The humanization of healthcare: A value framework for qualitative research. International Journal of Qualitative Studies on Health and Well-being 4, 68-77. 
Wainwright P, Thomas J \& Jones M (2000) Health promotion and the role of the school nurse: a systematic review. Journal of Advanced Nursing 32, 1083-1091.

Whiteman DC, Whiteman C \& Green A (2001) Childhood sun exposure as a risk factor for melanoma: a systematic review of epidemiologic studies. Cancer Causes and Control 12, 68-82.

Wichstrøm L (1994) Predictors of Norwegian adolescents' sunbathing and use of sunscreen. Health Psychology 13, 412-420.

World Health Organisation (WHO) (2007) Incidence of melanoma in people aged under 55 years. World Health Organisation. Regional Office for Europe. Available at: http://www.euro.who.int/_data/assets/pdf_file/0009/97443/4.2.pdf (accessed $8^{\text {th }}$ May 2013).

Wuest J (2012) Grounded Theory: The method. In: Nursing Research: A Qualitative Perspective (Munhall P ed.), Jones and Bartlett, London, pp. 225-256.

Young C (2009) Solar ultraviolet radiation and skin cancer. Occupational Medicine 59,82-88. 